\title{
Saturation Recovery Pulse Sequence
}

National Cancer Institute

\section{Source}

National Cancer Institute. Saturation Recovery Pulse Sequence. NCI Thesaurus. Code C151964.

A sequence of multiple 90 degree radio frequency pulses spaced at repetition times that allow the recovery of all the long itudinal magnetization before the next pulse. 